Running Head: Undervaluing Kindness

In press, Journal of Experimental Psychology: General

\author{
A Little Good Goes an Unexpectedly Long Way: \\ Underestimating the Positive Impact of Kindness on Recipients
}

\author{
Amit Kumar ${ }^{\mathrm{a}} \&$ Nicholas Epley ${ }^{\mathrm{b}}$ \\ ${ }^{\mathrm{a}}$ University of Texas at Austin ${ }^{\mathrm{b}}$ University of Chicago
}

WORD COUNT: 14,830

Abstract: 215

Portions of this research were presented virtually at the 2020 Association for Consumer Research Annual Meeting, at the 2021 Association for Psychological Science Annual Convention, and at the 2022 Society for Consumer Psychology Annual Meeting.

Correspondence concerning this article should be addressed to Amit Kumar, University of Texas at Austin, 2110 Speedway, B6700, Austin, TX 78712. E-mail:

Amit.Kumar@mccombs.utexas.edu

Data, materials, and pre-registrations are available at tinyurl.com/osf-undervaluing-kindness 


\begin{abstract}
Performing random acts of kindness increases happiness in both givers and receivers, but we find that givers systematically undervalue their positive impact on recipients. In both field and laboratory settings (Experiments 1a-2b), those performing an act of kindness reported how positive they expected recipients would feel and recipients reported how they actually felt. From giving away a cup of hot chocolate in a park to giving away a gift in the lab, those performing a random act of kindness consistently underestimated how positive their recipients would feel, thinking their act was of less value than recipients perceived it to be. Givers' miscalibrated expectations are driven partly by an egocentric bias in evaluations of the act itself (Experiment 3). Whereas recipients' positive reactions are enhanced by the warmth conveyed in a kind act, givers' expectations are relatively insensitive to the warmth conveyed in their action. Underestimating the positive impact of a random act of kindness also leads givers to underestimate the behavioral consequences their prosociality will produce in recipients through indirect reciprocity (Experiment 4). We suggest that givers' miscalibrated expectations matter because they can create a barrier to engaging in prosocial actions more often in everyday life (Experiments 5a-5b), which may result in people missing out on opportunities to enhance both their own and others' wellbeing.
\end{abstract}

Keywords: Prosocial Behavior; Social Cognition; Well-being; Happiness; Kindness Word Count: 215 


\section{A Little Good Goes an Unexpectedly Long Way: Underestimating the Positive Impact of Kindness on Recipients}

Each year on January 22nd, Austin, Texas holds its annual “Hi, How Are You?” Day. Residents of the city are encouraged on this day to reach out to friends and neighbors and simply ask how they're doing. The day was proposed under the premise that such seemingly small acts of kindness can make a significant difference in someone's life. That such random acts of kindness could seem to need explicit encouragement suggests that people may not be engaging in these prosocial acts as often in daily life as might be optimal. It is sometimes said that "a little good goes a long way." Here we present a series of experiments suggesting that a little good may go an unexpectedly long way. Specifically, our experiments suggest that those who perform acts of kindness systematically underestimate the positive impact they have on recipients, both on a recipient's wellbeing and their future kind behavior towards others. These miscalibrated expectations matter because they could create a psychological barrier to engaging in acts of kindness more often than would seem ideal to not only some residents of Austin, but to the givers and receivers of acts of kindness as well.

Prosociality and Wellbeing

Existing research makes it clear that positive interpersonal contact is a powerful source of wellbeing. Indeed, positive social relationships are critical—perhaps even necessary—for happiness and health (Diener \& Seligman, 2002; Heliwell \& Putnam, 2004; Luo, Hawkley, Waite, \& Cacioppo, 2012; Myers, 2000). For instance, in one nationally representative survey, the difference in reported affect between those who had versus had not interacted with another person the previous day was seven times larger than the difference in reported affect between those who were above versus below the approximate median income in this sample (see Table 1, 
Kahneman \& Deaton, 2010). Meta-analyses of mortality risks also suggest that lacking social support can be just as dangerous as well-known risk factors like cigarette smoking, obesity, and physical inactivity (Holt-Lunstad, Smith, \& Layton, 2010; House, Landis \& Umberson, 1988).

If positive social connections are critical for wellbeing, then one approach for improving wellbeing is obvious: be more prosocial. Indeed, a large literature now attests to the positive impact that prosocial actions can have people's own wellbeing (Chancellor, Margolis, Jacobs Bao, \& Lyubomirsky, 2018; Dunn, Aknin, \& Norton, 2008; Lyubomirsky, Sheldon, \& Schkade, 2005; see Curry, et al., 2018 for a meta-analysis). In one experiment, for example, consumers who spent money on someone else were happier than those instructed to spend money on themselves, both when they spent relatively little $(\$ 5)$ and when they spent relatively more $(\$ 20$; Dunn, et al., 2008). In another experiment, researchers randomly assigned employees in a corporate workplace to either be performers or receivers of random acts of kindness. Multiple measures of wellbeing improved in both groups, with a positive impact that lasted at least two months beyond the end of the experimental intervention. Notably, givers reported markedly weaker depressive symptoms and increased satisfaction with both their jobs and lives (Chancellor, et al., 2018). The positive consequences from prosocial actions have meaningful downstream consequences for givers, buffering against burnout and emotional exhaustion among professional fundraisers and public sanitation employees in one series of experiments (Grant \& Sonnentag, 2010), and increasing a giver's potential number of friends in another experiment with school-aged children (Layous, et al., 2012). Being good to others can also be good for oneself. 


\section{Undervaluing Prosociality?}

Despite the positive impact of prosociality for both givers' and receivers' wellbeing, several findings suggest that people may underestimate this positive impact in a way that might reduce prosociality in everyday life. In particular, prosocial acts are intended to have a positive impact on others, and yet people do not seem to fully realize just how positive others will feel following a prosocial act. In one experiment, people who wrote a letter expressing their gratitude — a well-documented activity for increasing a person's own wellbeing — systematically underestimated how positive their recipients would feel and overestimated how awkward recipients would feel (Kumar \& Epley, 2018; see also Epley et al., 2022). Although expressers expected that gratitude recipients would feel positive, recipients reported feeling even more positive than the expressers anticipated. Later extensions of this research found similar effects for expressing simple compliments to others (Boothby \& Bohns, 2021; Zhao \& Epley, 2021a, 2021b), as well as for expressing support to someone in need (Dungan, et al., in press).

These miscalibrated expectations about prosocial interactions matter because they may create a psychological barrier to prosocial behaviors that people could otherwise want to perform. For instance, those in need of help may underestimate how likely others are to agree to help when asked (Flynn \& Lake, 2008; Newark, Flynn, \& Bohns, 2017), and underestimate how positively others will feel after being asked to help (Zhao \& Epley, in press), thereby making people overly reluctant to request help when in need. Recent work has also found that people underestimate how interested others are in connecting through conversation (Epley \& Schroeder, 2014; Kardas, Kumar, \& Epley, 2022; Schroeder, et al., in press), and even underestimate how positively others will judge them after a conversation (Boothby, Cooney, Sandstrom, \& Clark, 2018), potentially discouraging people from reaching out and connecting with others they might 
want to connect with more often in daily life. In this way, being reluctant to engage in a prosocial action may not simply reflect a lack of approach-oriented (prosocial) motivation to engage with others, but rather can reflect an avoidance-oriented barrier based on concerns about how positively another person might respond (Epley et al., in press). In cases of approach/avoidance conflicts, underestimating how positively others might respond to a prosocial act could lead to missed opportunities for engaging with others that could increase one's own and others' wellbeing. Reducing this barrier by calibrating expectations about another person's response could then increase prosocial behavior by reducing avoidance motivation.

Here we suggest that these phenomena represent a broader tendency to underestimate the positive impact of prosociality on others, ranging from complete strangers to novel acts of prosociality with our closest friends and spouses, that creates a barrier to behaving more prosocially in everyday life. We test this hypothesis by focusing directly on behaviors that are specifically intended to make another person feel positive; that is, are specifically intended to be prosocial. We do this by testing the expected and actual consequences of behaviors framed as random acts of kindness. We define a random act of kindness as an unexpected prosocial act that someone could do for another person, done out of kindness towards another person with no expectation of receiving anything from the recipient in return. These acts are meant to be truly prosocial, in contrast to kind acts that might be expected by recipients and therefore performed out of a sense of obligation or duty, such as gifts given during holidays or for one's birthday.

We believe this work is both theoretically important and novel because random acts of kindness are unique from other prosocial actions studied so far in ways that might yield unique results. In particular, gratitude and compliments are prosocial expressions uniquely tailored to enhance the recipient's self-image typically by highlighting some positive attribute, which may 
create an especially positive experience for recipients (Zhao \& Epley, 2021a). Expressions of support (Dungan, et al., in press) come in cases when a recipient is in particular need, and hence may be uniquely appreciated in that moment. Random acts of kindness, in contrast, include a broader class of prosocial acts specifically intended to make another person feel positive, but not necessarily in ways that are uniquely tailored to a recipient's self-image or delivered in a specific time of need. Studying random acts of kindness is critical for programmatic research in order to determine the scope of people's tendency to undervalue the positive impact of their prosocial acts, and to understand the extent to which it might inhibit prosociality across a wide range of behaviors. We also examine broader consequences of prosociality than have been examined in prior research by studying indirect reciprocity (Experiment 4), and provide unique tests of the psychological mechanism underlying miscalibrated expectations that may apply to other forms of prosociality (Experiments 3 and 4).

Consistent with prior theorizing (Kumar \& Epley, 2018; Zhao \& Epley, 2021a; see also Flynn \& Brockner, 2003), we predict that people systematically undervalue the positive impact of prosociality due to a perspective-based asymmetry in the attention paid to competence versus warmth in evaluating interpersonal behavior. People tend to focus relatively more on competence when evaluating their own social behavior but tend to focus relatively more on interpersonal warmth when evaluating others' social behavior (Abele \& Wojciszke, 2007; Fiske, Cuddy, \& Glick, 2007; Wojciszke, 1994). This asymmetry could cause givers of an act of kindness to focus inordinately on the details of the act itself: the thing one is giving and its objective value. Recipients of an act of kindness, in contrast, also care about the thing being given but may focus relatively more on the positive intention and warmth conveyed by the act. A recipient's reaction to a prosocial act comes from the objective value of the act itself, plus the 
warmth conveyed by it. If givers focus on the act itself and do not take into account the additional value that comes from its interpersonal warmth, then they will systematically underestimate the positive impact of their prosocial action on recipients. Whereas those who perform a random act of kindness might construe their act as relatively "little," as if they are not doing much at all, recipients might instead construe the small act of kindness to be significantly "bigger" and of greater value than the performers expect.

\section{Overview of the Present Research}

We conducted eight experiments to test our hypothesis that people systematically underestimate the positive impact of their prosocial actions on others, that this miscalibration stems from failing to appreciate the importance of interpersonal warmth in a recipient's reaction, and that miscalibrated expectations can serve as a barrier to performing acts of kindness. These experiments test our hypotheses on a wide range of participants. Those performing random acts of kindness ranged from MBA students to university undergraduates to members of the public visiting an attraction in a large urban setting, whereas those receiving the act of kindness ranged even more widely as friends, family members, acquaintances, and strangers of the performers.

In Experiment 1a, participants in a field experiment chose to perform a wide variety of acts of kindness and evaluated how they thought their recipients viewed those acts. They also reported how they believed their recipients felt as a result of their acts. We compared these expectations to recipients' actual reports or behavior. Experiment $1 \mathrm{~b}$ followed a similar procedure holding the act itself relatively constant. Experiments $2 \mathrm{a}$ and $2 \mathrm{~b}$ provided additional tests of our hypotheses in designs that enabled perfect response rates, something we could not obtain in the field settings of Experiments 1a and 1b. Experiment 3 tested our proposed explanation for these results by comparing a random act of kindness condition against a control 
condition in which participants received the same objective gift but without it being the result of an act of kindness. Experiment 4 examined whether underestimating a recipient's emotional reaction also leads to underestimating a recipient's behavioral reaction, going beyond the selfreport measures of experience used in previous research. More specifically, kindness tends to spread through indirect reciprocity, such that people who have received an act of kindness are more likely to behave kindly towards another person in the future (Chancellor, et al., 2018; DeSteno, Bartlett, Baumann, Williams, \& Dickens, 2010; Gray, Ward, \& Norton, 2014). If people undervalue the positive impact of prosociality on others, then they should also underestimate the magnitude of indirect reciprocity it produces in others. Finally, Experiments 5a and $5 \mathrm{~b}$ tested whether people's expectations can create a misplaced barrier to engaging in prosocial acts.

\section{Experiment 1a: Many Acts of Kindness}

\section{Method}

Transparency and Openness. For this and all studies, we report how we determined our sample size in advance, any data exclusions (when applicable), and all manipulations and measures. Data and materials, as well as pre-registrations for the design, hypotheses, and analysis plan for Experiments 5a and 5b, are available at tinyurl.com/osf-undervaluing-kindness. Earlier experiments were not pre-registered because we conducted them before pre-registrations were adopted as standard practice in the field. We include multiple replications of these experimental procedures to test their robustness. We obtained informed consent from all participants. 
Participants. One hundred six MBA students $\left(40\right.$ female $\left.^{1} ; M_{\mathrm{age}}=29.12, S D=2.86\right)$

participated in a voluntary class exercise. This sample size was the total number of students in the course who completed the exercise and consented to using their data for research purposes. The students performed a total of 192 acts of kindness for different recipients. Due to the naturalistic methods employed here, in which participants simply went out into the world to perform any random act of kindness for another person, we observed considerable attrition. Some students did not grant permission to send surveys to recipients (or did not have this contact information), and some recipients did not get back to us. In total, we were given permission to contact 86 recipients, of whom 66 completed the survey reporting on their experience (37 female; $\left.M_{\text {age }}=31.20, S D=8.74\right)$, yielding a $77 \%$ response rate for recipients. These 66 pairs of performers and recipients comprise the sample for the primary analyses described below.

This attrition could prompt concerns that selection effects are producing an artifact in our results. If those who could not be contacted, or who did not respond, are different from those who were contacted and did respond, then our results could be systematically distorted.

However, we do not believe selection is responsible for the effects we document for two reasons. First, we find converging evidence using a multi-method approach, including experiments that have perfect response rates from both performers and recipients (see Experiments $2 \mathrm{a}-4$ below). Second, we do not observe consistent or meaningful differences between the evaluations of performers whose recipients responded compared to those whose recipients did not respond. Evaluations from the 66 performers in this experiment for whom we have recipient data do not differ from evaluations for those recipients who were contacted but did not respond on all items

\footnotetext{
${ }^{1}$ Although we did not anticipate gender differences, we nevertheless tested for them following a suggestion by an anonymous reviewer. Specifically, we tested for the existence of gender effects on participants' expectations, experiences, and the difference between them. We did not observe reliable differences by gender across experiments and thus do not discuss this further. Details of these additional analyses can be found at: tinyurl.com/osfundervaluing-kindness
} 
( $p$ s range from .13 to .90), nor do they differ from evaluations for the acts for which no recipient contact information was provided ( $p$ s range from .13 to .91). At the very least, performers were not systematically allowing us to contact only those they thought would respond favorably.

Procedure. Performers received instructions for this experiment during a classroom session, followed by a reiteration of these instructions in an email. We asked participants to perform two random acts of kindness for someone else, ideally one to a stranger and one to a friend over a two-day period, instructing them to give to another person while expecting nothing in return. For the kind act to a friend, we further encouraged participants to do something nice for another student in their MBA program who was not in their class because we assumed this would increase the likelihood that they would know their recipient's email address (and hence could be contacted), but participants were also told that they could perform their act of kindness for someone else if they preferred.

We asked participants to perform any act of kindness they could think of, noting that the act could be large or small, anonymous or identified, planned or spontaneous, and could include sacrifices of time, energy, or money. We included several examples, such as "helping another student complete a task above and beyond what is normally expected," "bringing someone a beverage, such as a soda, energy drink, hot coffee, or tea, without them asking," "paying for someone's order at a café," "giving someone a gift card to a favorite store or restaurant," and "making a special attempt to recognize someone when they might otherwise be overlooked." We adapted this method from Chancellor, et al. (2018).

After performing their acts of kindness, participants completed a questionnaire reporting their own experience and evaluating their recipient's experience. Performers first indicated their own name, and then named the recipient of their act of kindness (if known). We asked 
participants to report their recipient's email address, if they knew it and were willing to have us send a brief survey to this person. They additionally reported when they performed their act of kindness and provided some detail on what they did in an open-ended fashion. Participants then rated how "big" the act of kindness was from their perspective on a scale ranging from 0 (Very small) to 10 (Very large) and reported whether it was anonymous or identifiable and whether it was planned or spontaneous. Next, participants reported how much time, money, and energy they sacrificed by performing the act, all on 11-point scales ranging from 0 (None at all) to 10 (Very much). We asked about the overall subjective value of the act—how "big" it seemedalong with more specific aspects of value such as time, effort, or money spent. We did not ask participants to estimate an act's objective financial value because we expected many of the acts of kindness would involve acts of symbolic value. We therefore conceptualized the measure of "how big" the act seemed as a measure of its expected or experienced utility from the recipient's perspective.

Most important, participants reported their recipient's mood as a result of their act of kindness on a scale from -5 (Much more negative than normal) to 5 (Much more positive than normal), with the midpoint (0) labeled "No different than normal." Participants also reported how awkward this person felt after they had been kind to them on a scale from 0 (Not at all) to 10 (Extremely). Participants reported their own feelings after performing the act on the same scales.

Finally, participants indicated how often, per month, they performed random acts of kindness and were then asked to report whether they thought the frequency with which they did acts like these was too little, too much, or just the right amount. They did this by responding to the following item: 
“Think about how often you typically perform random acts of kindness like this. Sometimes people feel they do certain activities too rarely (for example, many people think they exercise too little). Other times people feel they do activities too often (for example, many people think they procrastinate too much). And still other times people think their behavior is just right, such as spending just the right amount of time on work or leisure activities. When thinking about how often you typically perform random acts of kindness, do you feel that you do this less often than you'd like to, more often than you'd like to, or is your frequency just about right?"

Participants responded on an 11-point scale where -5 represented "I do this much less often than I'd like," 0 represented "just about right," and 5 represented "I do this much more often than I'd like." The survey ended by asking participants to report their age and gender.

We contacted all possible recipients over email on the morning after a performer completed his or her questionnaire. Recipients were reminded of the act of kindness — based on the description the performer provided - and were asked to complete a voluntary and confidential online survey reporting their experience. This survey asked recipients to report their name, the name of their performer, how "big" they perceived this act of kindness to be, how much time, money, and energy they thought the performer had sacrificed for them, and their mood and awkwardness felt as a result of this act. All items used the same scales as performers.

\section{Results}

Participants engaged in many different acts of kindness, including purchasing coffee, offering rides home, delivering flowers, and baking for others. Although not the primary purpose of this experiment, performing a random act of kindness was a positive experience for participants, consistent with prior research (e.g., Chancellor, et al., 2018; Dunn, et al., 2008). 
Performers reported being in a significantly more positive mood than normal after doing a kind act for someone else $(M=2.07, S D=1.35)$, one-sample $\mathrm{t}(191)=21.25, p<.0001, d=1.53$. We observe the same result when analyzing only the subset of acts for which we have complete data from recipients $(M=2.08, S D=1.21)$, one-sample $\mathrm{t}(65)=13.98, p<.0001, d=1.72$.

More important for our current hypotheses, Figure 1 shows that performers underestimated the positive impact they would have on recipients. Performers reported that their act was not as "big" as recipients perceived it to be, paired $t(65)=9.64, p<.0001, d=1.20$, and also reported expending less time, money, and energy than the recipients believed the performers had expended, $t \mathrm{~s}=5.48,4.49$, and 6.83, respectively, $p \mathrm{~s}<.0001, d \mathrm{~s}=0.57,0.60$, and 0.87 . Although performers reported that their recipients felt quite positive, recipients actually reported feeling even more positive, paired $t(65)=6.53, p<.0001, d=0.83$. Performers also thought their recipient felt more awkward than the recipients actually did, paired $t(64)=-2.28, p=.026$, $d=.29 .^{2}$ Together, these results indicate that performers systemically underestimated the positive impact their act of kindness would have on recipients.

${ }^{2}$ One participant did not provide a response to the question asking about the recipient's anticipated feelings of awkwardness and this pair is excluded from the last analysis only, as reflected in the reported degrees of freedom for that test. 


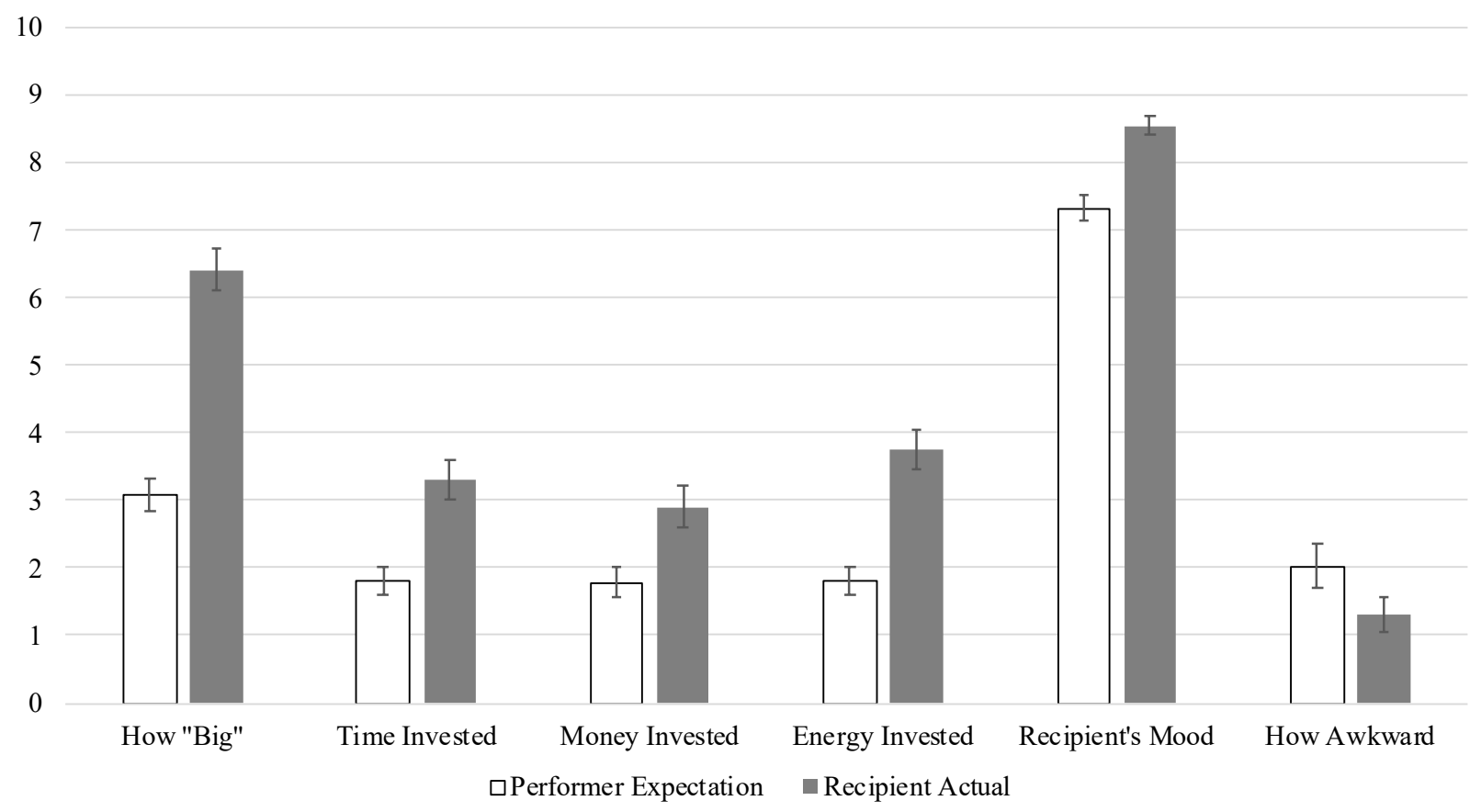

Figure 1. Performers' expectations and Recipients' experiences following an act of kindness in Experiment 1a. All items were answered on response scales ranging from 0-10 except for mood, which was made on a scale ranging from -5 (Much more negative than normal) to 5 (Much more positive than normal). We rescaled this item for use in this figure by adding 5 to each participant's response. Error bars reflect standard errors.

Finally, all performers reported how often they engage in these sorts of actions, compared to how often they would like to. These performers tended to say they did random acts of kindness less often than they would like $(M=-1.69, S D=1.80), t(105)=-9.68, p<.0001, d=$ 0.94, suggesting that most of our participants viewed their own current behavior as somewhat suboptimal. Misunderstanding how positively recipients will respond to a kind gesture may leave people choosing to engage in kindness less often than they would actually want to, thereby representing a barrier to prosocial interactions that could be suboptimal for both their own and others' wellbeing. 


\section{Experiment 1b: One Kind Act, Many Times Over}

In this conceptual replication of Experiment 1a, we sought to standardize the act of kindness such that everyone was engaging in a relatively similar act of prosocial behavior towards another person. We also recruited from a different sample to examine the robustness of our results. Participants mailed a letter to someone for the purpose of doing something nice and then predicted how their recipients would feel. We followed up with those recipients and allowed them to report how they actually felt.

\section{Method}

Participants. One hundred participants (58 female; $M_{\mathrm{age}}=20.44, S D=3.47$ ) recruited on the campus of a private midwestern university completed this experiment in exchange for $\$ 1$. We targeted this pre-determined sample size because we expected a response rate of at least $50 \%$, based on similar studies conducted in this context, which would still yield a minimum of 50 pairs for our main analyses comparing performers' expectations to recipients' actual experiences.

Of the 100 participants who wrote a note, one participant could not find the mailing address of their recipient and therefore did not send a card. This participant is excluded from the analyses reported below. Although all of the remaining participants agreed to let us contact their recipients with a follow-up survey, an additional four provided an email address that was either incorrect (e.g., due to a typographical error) or no longer functioning, preventing us from reaching those individuals. We therefore sent questionnaires to 95 recipients, of whom 57 responded. Two of these participants, however, reported that they did not actually receive a card from a friend in the mail yet, presumably because of postal service delays. This left a final sample of 55 recipients ( 41 female; $M_{\text {age }}=30.65, S D=17.76$ ), yielding a $58 \%$ response rate. Expectations from participants whose recipient responded did not differ from those whose 
recipient did not respond on most items $(p s=.64, .57$, and .70 for time invested, energy invested, and mood, respectively), with the only exceptions being that performers whose recipient did not respond expected that their act would be perceived as bigger $(p=.01)$ and make their recipient feel marginally more awkward $(p=.05)$. This again suggests that participants were not systematically allowing us to contact only people whom they thought would respond especially favorably. As in Experiment 1a, nonresponses could produce an artifact in our results if the nonrespondents were systematically different than those who responded. We again address this in Experiments $2 \mathrm{a}$ and $2 \mathrm{~b}$ by examining a context with perfect response rates.

Procedure. Participants were recruited for a study on writing notes to people. On arrival to the laboratory, participants first reported their mood before receiving instructions in order to serve as a baseline for comparison, on a scale ranging from -5 (much more negative than normal) to 5 (much more positive than normal), with 0 labeled as "no different than normal."

The experimenter then showed participants an array of different greeting cards and asked them to choose their preferred design and to simply write a nice note to someone else. They were told that we would cover the postage and mail it for them on their behalf. The instructions indicated that participants could write a note for any reason at all, but that they should "think of this as sort of a random act of kindness you could do for another person." We provided examples as possibilities: "maybe this person has been having a tough time lately and you want to cheer them up, maybe you haven't seen them much recently and just want to check in, maybe something that happened to you in the past few days reminded you of them, or perhaps you'd like to send them a note just because."

Participants were also told that they could send a card to anyone they liked: "relatives, friends, teachers, coaches, teammates, employers, and so on.” Providing a broad range of 
prospective recipients potentially expanded the pool of recipients compared to Experiment 1a (in which participants were encouraged, but not restricted, to perform a random act of kindness for another professional student at their school). Although the instructions indicated that they could write to whomever they wished, they also made clear that this should be someone whose mailing address they knew off-hand or could easily look up. Participants were further informed that we intended to send recipients of these cards a brief questionnaire after their note was delivered. As a result, they were told that they could let their recipient know that this act was prompted by an experiment they were participating in and that they would receive a survey in their email, which they could fill out if they wanted. We requested that participants choose recipients whose email address they knew or could quickly look up. Participants then took a few minutes to write a card to their recipient.

Immediately after writing their note, performers completed a questionnaire reporting their own experience and predicting their recipient's experience, similar to the one in Experiment 1a. This survey for performers included all of the same items as in Experiment 1a, with a couple of exceptions. It did not include a measure of how much money was invested in the act of kindness because we provided the cards and paid for mailing expenses, so performers did not have to invest any monetary resources in this experiment. The only costs included were of time and energy. The questionnaire also did not include the item about how often participants engaged in kind acts like this one.

We mailed participants' notes through the U.S. Postal Service. Because it would take some time for these cards to arrive in the mail, we contacted recipients via email one week after sending them. In this email, recipients were first informed that a person affiliated with the university recently sent them a card in the mail. They were explicitly told that we provided these 
cards to members of the community as part of an experiment we were conducting, so that they could send a note to someone with whom they wanted to get in touch. The questionnaire for recipients was identical to the recipient survey in Experiment 1a, except that it did not include the question about their perception of the amount of money that was sacrificed by the performer. Recipients reported how "big" they thought this act to be, how much time they thought the performer sacrificed, how much energy he or she sacrificed, how negative or positive they felt after reading the note (compared to how they normally feel), and how awkward they felt as a result of this act. All of these responses were provided on the same scales as Experiment 1aand therefore on the same scales as the letter writers' predictions.

\section{Results}

As in Experiment 1a, performing an act of kindness was a positive experience. Performers again reported being in a significantly more positive mood than normal $(M=2.35$, $S D=1.61)$, one-sample $\mathrm{t}(98)=14.53, p<.0001, d=1.46$, and also reported being in a more positive mood after writing their note than they reported feeling at the beginning of the experiment $(M=0.69, S D=1.71)$, paired $t(98)=8.42, p<.0001, d=0.85$.

More important, Figure 2 shows that performers again underestimated the positive impact they would have on recipients. Performers reported that their act was not as "big" as recipients perceived it to be, paired $t(54)=7.02, p<.0001, d=0.95$, and also reported expending less time and energy than the recipients believed the performers had expended, respective $t \mathrm{~s}=7.54$ and 5.27, $p \mathrm{~s}<.0001, d \mathrm{~s}=1.10$ and 0.72. As in Experiment 1a, performers again expected the recipients to feel positive, but they still significantly underestimated how positive recipients reported actually feeling, paired $t(54)=2.07, p=.044, d=0.28$. However, unlike Experiment 1a, performers did not significantly overestimate recipients' feelings of awkwardness, paired 
$t(54)=-0.68, p=.500, d=-0.09$. Unlike the items measuring positive impact, differences between performers' expectations and recipients' experiences on awkwardness seem to vary by context. We will return to this issue in the General Discussion.

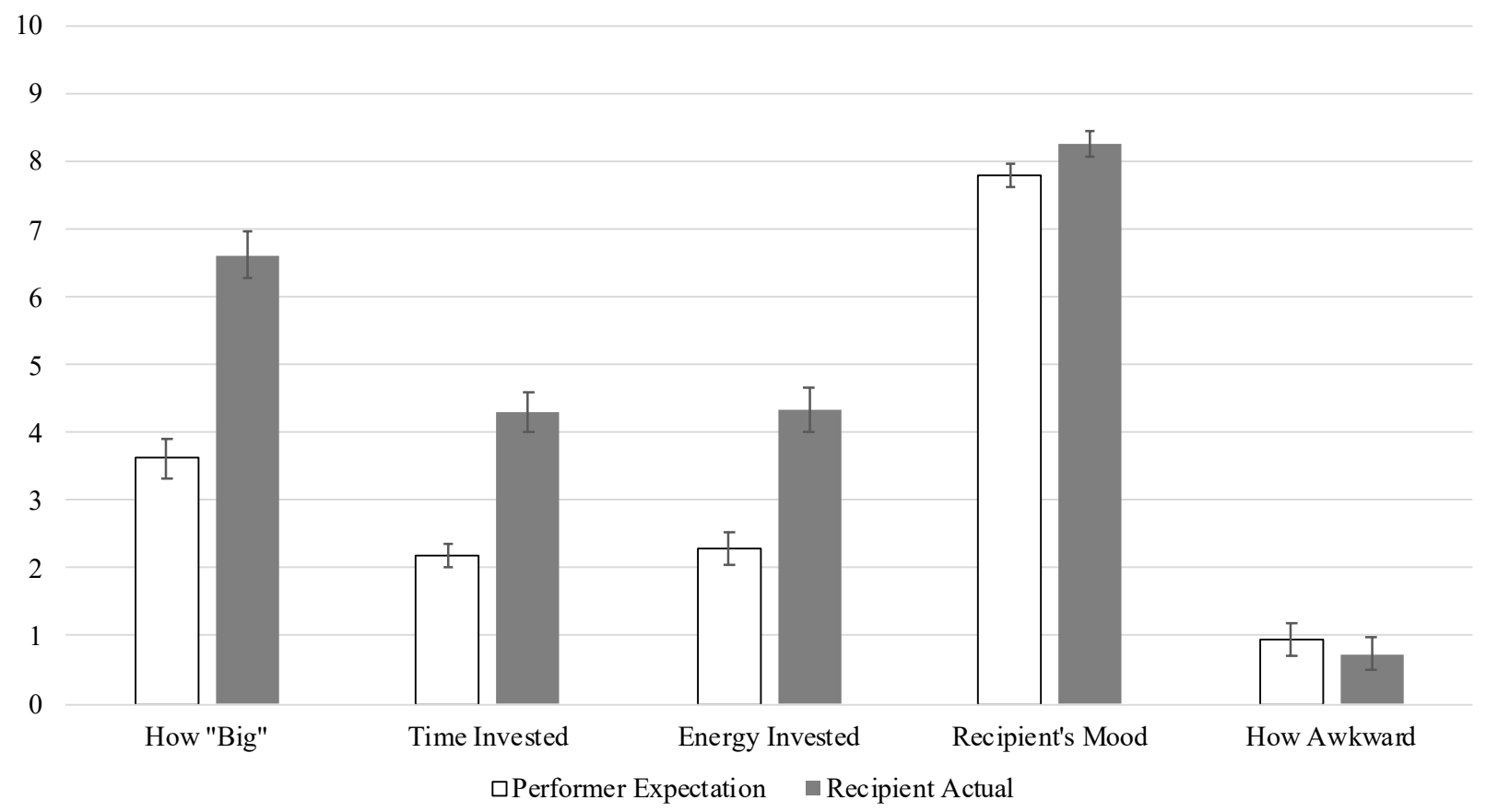

Figure 2. Performers' expectations and Recipients' experiences following an act of kindness in Experiment 1b. All items were answered on response scales ranging from 0-10 except for mood, which was made on a scale ranging from -5 (Much more negative than normal) to 5 (Much more positive than normal). We rescaled this item for use in this figure by adding 5 to each participant's response. Error bars reflect standard errors.

\section{Experiment 2a: Hot Chocolate at the Skating Rink}

Although Experiments $1 \mathrm{a}$ and $1 \mathrm{~b}$ are consistent with our hypotheses, they include a feature common to naturalistic field studies: imperfect response rates. To test our hypotheses in a 
context without this feature, we conducted another field experiment in which participants performed a random act of kindness for a nearby stranger who was then surveyed immediately afterwards. Specifically, we recruited participants at a large public ice-skating rink and had them give away a hot chocolate to someone in the immediate area. We predicted that those giving away the hot chocolate would not perceive it to be as valuable an act as those receiving it did, and that givers would underestimate how positive the act would make recipients feel.

\section{Method}

Participants. We received permission to conduct an experiment over the course of two weekends at a skating ribbon in a public park in the downtown area of a major U. S. city. We were able to recruit a total of 84 participants during this time, who we asked to give away a cup of hot chocolate to another person. In order to provide participants with some sense of agency over the act of kindness, we told participants that they could keep the hot chocolate we obtained from the park's snack kiosk for themselves or could give it away to a stranger at the rink as a random act of kindness. They were encouraged by the experimenter to give it away in order to test our primary hypotheses of interest, but the experimenter also reminded participants that they were free to choose to keep it for themselves instead if they preferred. To encourage giving while still maintaining the option of keeping the item, participants were instructed that it would be helpful for the purposes of the study if they gave the hot chocolate away to someone else, but that if they did so, they should not anticipate anything in return for their kindness, such as being thanked, appreciated, or engendering some future favor. Nine participants chose to keep the hot chocolate, and 75 agreed to give it away as a kind act (43 female; $M_{\text {age }}=31.68, S D=10.26$ ). These 75 participants comprised our final sample of performers who then continued with the experiment, completing survey items about the experience. After each participant agreed to give 
away the hot chocolate, we approached the designated recipient. All 75 recipients we approached agreed to participate (57 female; $\left.M_{\text {age }}=31.29, S D=9.80\right)$.

Procedure. If participants agreed to perform a random act of kindness - in this case, giving away a hot chocolate to another person at the skating rink - they were asked to point out a stranger in the area to serve as the recipient of the act. Participants then answered three questions of primary interest before providing demographic information. First, how "big" the act of kindness was from their perspective, on a scale ranging from 0 (Very small) to 10 (Very large). Second, to report their own mood as a result of performing this act of kindness, on an 11-point scale ranging from -5 (much more negative than normal) to 5 (much more positive than normal). Third, participants predicted the recipient's mood on the same 11-point scale. We reduced the number of items compared to the preceding experiments because of time constraints that come from running an experiment in this field setting.

The experimenter then delivered the hot chocolate to the recipient. The experimenter explained to all recipients that the person who gave them their hot chocolate "was told that one participant per pair in this study was able to receive a cup of hot chocolate. While your partner was able to keep this hot chocolate for himself or herself, he or she instead chose to give it to you." After receiving the hot chocolate, recipients were asked to indicate on a survey how "big" the act seemed to them and to report their mood, using the same scales as the givers described above. Recipients then reported their age and gender and were thanked and debriefed.

\section{Results}

Although not critical to the current investigation, performers of an act of kindness reported feeling significantly more positive than they typically do $(M=2.40, S D=1.41)$, one- 
sample $\mathrm{t}(74)=14.70, p<.0001, d=1.70$. This result is consistent with past research demonstrating increased wellbeing from prosocial behavior.

More important for present purposes, givers again underestimated the positive impact they would have on recipients. Givers again reported that their act was not as "big" ( $M=3.76$, $S D=2.41)$ as the recipients perceived it to be $(M=7.00, S D=1.89)$, paired $t(74)=9.97, p<$ $.0001, d=1.16$. Although givers did recognize that giving away a cup of hot chocolate on a cold winter day would make recipients feel more positive than normal $(M=2.73, S D=1.36)$, they still significantly underestimated how positive it would actually make recipients feel $(M=3.52$, $S D=1.17)$, paired $t(74)=4.10, p=.0001, d=0.48$. As in the preceding experiments, those who received an act of kindness again thought the act was bigger than did performers, and also felt significantly more positive than the performers expected.

\section{Experiment 2b: A Kind Gift}

Experiment $2 \mathrm{~b}$ provided one more direct test of our hypothesis by having one participant give another a gift as an act of kindness in the laboratory. This setting increases the likelihood of obtaining perfect compliance with our request to perform an act of kindness, ensures perfect response rates among recipients, and further tests the robustness of our primary hypotheses. We again predicted that those who gave a gift to another person as an act of kindness would underestimate their positive impact on recipients: that givers would value the act as less "big" than recipients, and that givers would underestimate the recipient's positive mood.

\section{Method}

Participants. Participants ( $N=102,51$ pairs) recruited to a laboratory on the campus of a private midwestern university completed this experiment in exchange for $\$ 1$. We targeted 50 pairs of participants. One extra pair participated because they were scheduled by mistake while 
what was meant to the final pair was completing the experiment. Two of the performers chose to keep an item for themselves instead of giving it away as the experimenter encouraged them to, leaving a final sample of 49 performers $\left(24\right.$ female; $\left.M_{\mathrm{age}}=20.73, S D=3.60\right)$ and 49 recipients (31 female; $\left.M_{\text {age }}=21.82, S D=6.60\right)$.

Procedure. Participants were recruited for an experiment on how people evaluate certain actions. On arrival to the laboratory, participants were paired up with a stranger they had never interacted with before and were randomly assigned to the role of either performer or recipient.

Performers were led to a room with five items on display: a fair-trade chocolate bar, organic popcorn, a box of gourmet tea bags, a package of cheese crackers, and a tube of natural beeswax lip balm. The experimenter explained that these were items from "our lab store" and that we were able to give one participant in each pair one of the items as additional compensation. Although told that they were free to select one of the items for themselves, the experimenter explained that it would help with the purposes of the study if they instead picked one out to give to their partner as an act of kindness. If they agreed to perform this act, the experimenter would bring the item to the recipient in the study and explain that their partner chose to give the item to them instead of keeping it for themselves. Performers were instructed not to anticipate getting anything in return for their kindness. Performers who agreed to give an item away then chose one for their partner, the experimenter took the item to the recipient, and the performer answered the three measures used in Experiment 2a, estimated the dollar value of the item, and also predicted how awkward the recipient would feel (as in Experiments 1a and 1b). We expected that the results for this measure of the estimated objective cost of the item would be similar to the results observed with the subjective measure of money expended from Experiment 1a. 
The experimenter then gave recipients their gift chosen by their performer. Recipients were told: "Your partner just saw an array of items from our 'lab store.' As an additional form of compensation for participation, one participant per pair was able to take home one of the available items. While your partner was able to keep the item for himself or herself, he or she instead chose to give the item to you." Recipients then completed a survey asking them to indicate "how big" the act of kindness seemed to them, how negative or positive they felt as a result of it, how awkward they felt, and how much they thought the item that was given to them was worth in dollars and cents. These responses were all made on the same scales used by performers.

\section{Results}

Once again, performing an act of kindness was a positive experience. Performers reported feeling significantly better than they typically feel $(M=1.61, S D=1.27)$, one-sample $\mathrm{t}(48)=$ $8.87, p<.0001, d=1.27$.

More important, performers again underestimated the positive impact that their prosocial act would have on the recipient. Specifically, performers rated their act of kindness as less "big" $(M=2.67, S D=2.21)$ than recipients $\operatorname{did}(M=7.27, S D=2.03)$, paired $t(48)=10.25, p<.0001$,

$d=1.47$. Estimates of the dollar value of the gift were in the same direction between roles but did not differ significantly between performers $(M=\$ 3.45, S D=1.73)$ and recipients $(M=$ $\$ 3.95, S D=1.59)$, paired $t(48)=1.51, p=.138, d=0.22$.

Performers again recognized that recipients would feel in a more positive mood than normal $(M=2.08, S D=1.26)$, but recipients again were in an even more positive mood than performers expected $(M=3.47, S D=1.06)$, paired $t(48)=5.50, p<.0001, d=0.79$. As in Experiment 1b, the difference between performer expectations of recipients' feelings of 
awkwardness $(M=2.47, S D=2.36)$ and their recipient's actual experience $(M=3.18, S D=$ 2.92) was statistically nonsignificant, paired $t(48)=1.41, p=.164, d=0.20$. We will return to the inconsistent results for awkwardness in the General Discussion.

\section{Experiment 3: Uniquely Undervaluing Kindness?}

Four experiments in both field and laboratory settings involving contexts with naturally chosen acts of kindness or experimentally induced acts of kindness all suggest the same general result: those who perform prosocial acts of kindness undervalue the positive impact that their actions will have on recipients.

These four experiments do not, however, explain why this discrepancy exists. One plausible mechanism, we suggest, is that a recipient's positive experience of another's prosocial act comes not only from the objective value of the act itself but also from additional value created by the interpersonal warmth conveyed through the act. Performers, in contrast, may be relatively insensitive to this additional value because they are not experiencing it directly, creating a perspective gap in emotional experience that can be hard to fully appreciate (Epley, Keysar, Van Boven, \& Gilovich, 2004; Van Boven, Loewenstein, Dunning, \& Nordgren, 2013), and because actors tend to evaluate their own behavior in terms of its competence (Abele \& Wojciszke, 2007). Those who perform kind acts may therefore be attending more to the details of what they actually did for the other person-how much, say, another person will like a free cup of hot chocolate - than to the warmth also conveyed by the action - that the hot chocolate was also a gift given in kindness. If so, then recipients should be significantly happier when they receive a gift as an act of kindness than when they receive the same gift without it being the result of an act of kindness. People's expectations about recipients' responses, however, may be relatively insensitive to this difference. 
We tested this mechanism in Experiment 3 by conducting a field experiment similar to Experiment $2 \mathrm{a}$ in which we also included a "no act of kindness" control condition such that recipients simply received an item from the experimenter for participating. We compared this to a kindness condition in which recipients were given the same item from another person as an act of kindness, as in Experiment 2a. We predicted that recipients would report a more positive and valuable experience in the kindness condition than in the control condition, but that those estimating their responses would anticipate more similar experiences for recipients in these two conditions. This further predicts that performers will underestimate the recipient's positive experience more in the kindness condition than in the control condition.

\section{Method}

Participants. We targeted recruitment of 100 pairs in order to obtain 50 in each of two experimental conditions. We recruited participants in a large public park, in the area surrounding a popular climbing wall attraction. In the control condition, we recruited 50 individuals who received a cupcake for their participation ( 35 female; $\left.M_{\text {age }}=39.24, S D=9.93\right)$ and another 50 individuals (33 female; $M_{\text {age }}=36.76, S D=9.16$ ) who estimated how each of these recipients would feel about his or her experience. In the kindness condition, which replicated the procedure of Experiment 2a, we recruited 50 performers who were asked to give away a gift to another person as an act of kindness (namely, to give away a cupcake that they could have instead kept for themselves). All but one of these participants (29 female; $M_{\mathrm{age}}=38.61, S D=10.29$ ) followed the experimenter's encouragement and gave a cupcake to 49 different strangers whom they had never met before ( 35 female; $M_{\text {age }}=37.65, S D=11.24$ ). As before, all performers were told to give while expecting nothing in return. 
Procedure. We recruited participants at the park for an experiment on evaluating actions. In both the act of kindness and control conditions, one participant received a large cupcake and the other participant in the pair estimated how "big" the recipient would interpret the act to be, as well as how the recipient felt.

Participants in the kindness condition experienced the same procedure as in Experiment 2a, except that recipients were given a cupcake rather than a cup of hot chocolate. We conducted Experiment 2a during the winter but conducted Experiment 3 during the summer when hot chocolate was neither desirable nor available from the snack kiosk.

To test our proposed explanation, recipients in the control condition also received a cupcake but were told that they were randomly assigned to receive it as part of the experiment, which we expected would be less likely to be perceived as a prosocial act of kindness compared to recipients in the act of kindness condition. Specifically, recipients in the control condition were told that "People often want a snack when they're out and about here at [park name redacted]. As compensation for participating in our studies, we've been able to ensure that one participant per pair gets a reward from the snack kiosk. You've been selected as the person in your pair to receive a snack from the experimenter. Today's item is a cupcake for your participation." These participants were then given their cupcake and asked to respond to two dependent measures. They first rated how "big" of an event receiving this item from the experimenter was from their perspective, on a scale from 0 (Very small) to 10 (Very large). Recipients then reported how negative or positive receiving the item made them feel, compared to how they normally felt, on an 11-point scale like the ones described above $(-5=$ Much more negative than normal; $0=$ No different than normal; $5=$ Much more positive than normal). 
After receiving a cupcake, each recipient in the control condition was paired with a specific participant who served as an estimator. These estimators were told, "This is a study about how people feel when they receive certain items. You'll be responding to a few questions involving another person here at the park today — a stranger you don't already know (who we'll refer to as your partner in the study). People often want a snack when they're out and about here in [park name redacted]. As compensation for participating in our studies, we've been able to ensure that one participant per pair gets a reward from the snack kiosk. Your partner was selected as the person in your pair who got to receive a snack from the experimenter. They received a cupcake from the kiosk for their participation." These participants then estimated how "big" the recipient would interpret the act to be, and estimated his or her mood, on the same scales used by recipients.

\section{Results}

Participants who performed a prosocial act reported feeling significantly better than they usually do $(M=2.90, S D=1.94)$, one-sample $t(48)=10.46, p<.0001, d=1.49$, and also felt significantly better than estimators in the control condition $(M=1.02, S D=2.67)$ who did not perform an act of kindness, unequal variances $t(89.50)=4.01, p=.0001, d=0.82$. This provides yet more evidence that performing prosocial actions increases a person's wellbeing.

As in the preceding experiments, performers in the kindness condition underestimated the positive impact they would have on recipients. Specifically, performers rated their act of kindness as less "big" $(M=6.35, S D=2.13)$ than recipients did $(M=7.41, S D=2.04)$, paired $t(48)=2.68, p=.010, d=0.38$. Performers again recognized that recipients would feel in a more positive mood than normal $(M=2.96, S D=1.57)$, but recipients again were in a more positive mood than performers expected $(M=3.51, S D=1.57)$, paired $t(48)=1.96, p=.056, d=0.28$. 
Notably, we did not observe significant miscalibration in the control condition.

Evaluations of how "big" the event seemed did not differ between estimators $(M=5.70, S D=$ $2.23)$ and recipients $(M=5.62, S D=2.75)$, paired $t(49)=-0.15, p=.881, d=0.02$. Estimators $(M=2.72, S D=1.94)$ also did not significantly underestimate the recipient's $\operatorname{mood}(M=2.86$, $S D=1.84)$, paired $t(49)=0.36, p=.719, d=0.05$.

As can be seen in Figure 3, these results emerged because recipients' estimates of how "big” the act seemed differed significantly across conditions, $t(97)=3.67, p<.001$, but expectations did not differ significantly between conditions, $t(97)=1.48, p=.143$. This pattern yielded a marginally significant 2 (condition: kindness vs. control) x 2 (role: performer vs. recipient) interaction, $F(1,97)=2.95, p=.089$. The interaction effect was nonsignificant on the mood measure, $F=0.73, p=.394$, although an inspection of the simple effects revealed a similar pattern. Expectations of the recipient's mood did not differ significantly between conditions, $t(97)=0.67, p=.502$, but there was a marginally significant difference in mood between recipients in the kindness and control conditions, $t(97)=1.89, p=.062$. 


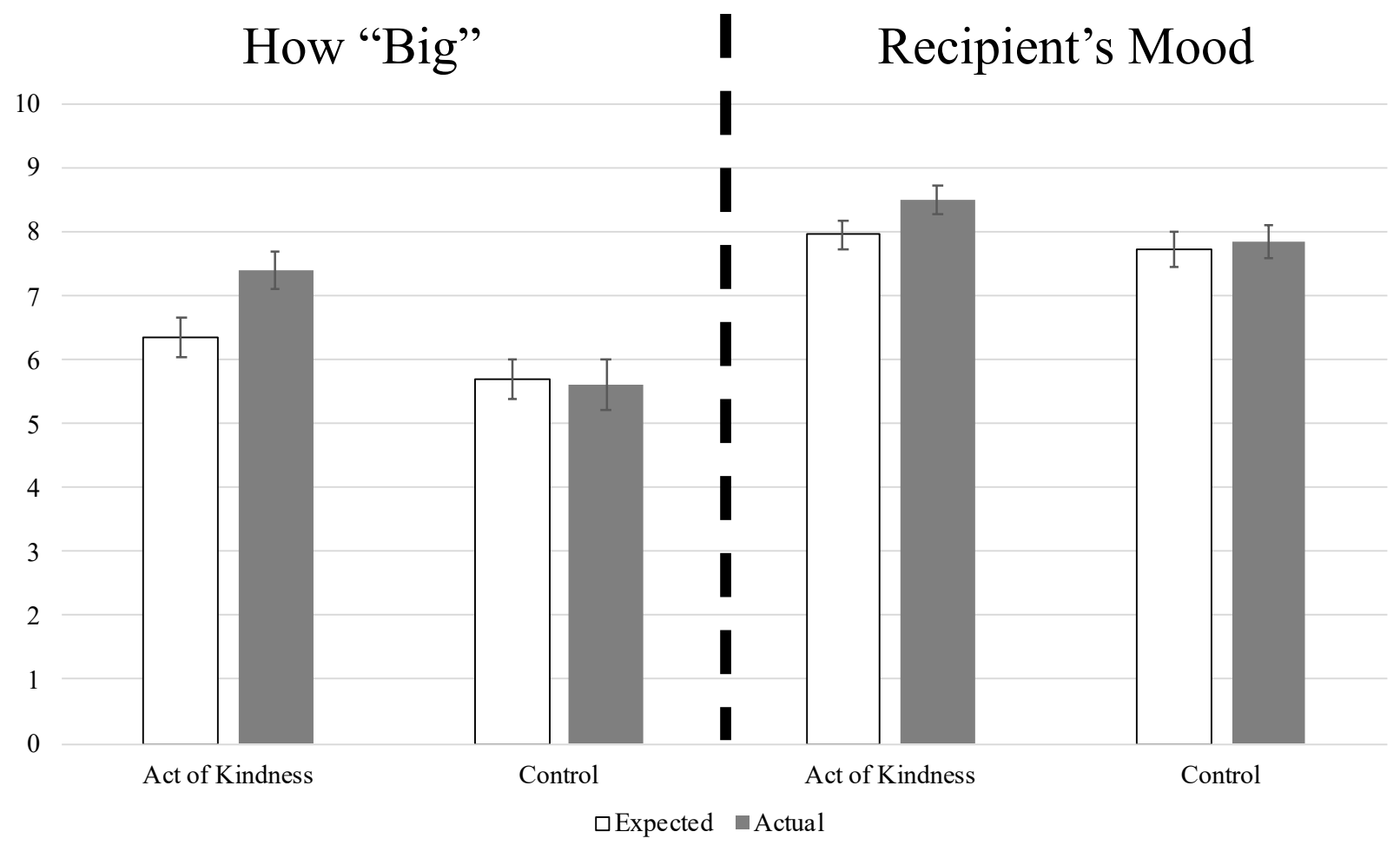

Figure 3. Expectations and actual experiences, either following an act of kindness or not, in Experiment 3. The mood item was answered on a response scale ranging from -5 (Much more negative than normal) to 5 (Much more positive than normal). We rescaled this item for use in this figure by adding 5 to each participant's response. Error bars reflect standard errors.

These results suggest that the mistaken expectations observed in the experiments thus far may be larger to the extent that an act is perceived to be prosocial. Receiving a cupcake felt good to recipients, and people generally recognized this. However, receiving a cupcake as a random act of kindness from a stranger felt a bit better, an effect that performers did not seem to fully appreciate. This suggests that those who perform acts of kindness may underestimate their positive impact because they do not fully anticipate the additional value a recipient will get from being the recipient of a prosocial act, in particular.

\section{Experiment 4: Underestimating Indirect Reciprocity}


The preceding experiments all suggest that those who perform an act of kindness may systematically undervalue its positive impact on recipients. Although these effects were reasonably large and robust, we only tested our hypotheses on participants' self-reported experiences. Kindness, however, also creates behavioral consequences by encouraging recipients to behave more prosocially towards others in the future. That is, experiencing kindness can encourage indirect reciprocity such that one act of kindness is "paid forward" to others (Gray et al., 2014). In one field experiment, those on the receiving end of a kind act reported engaging in more kind actions towards others as a result, compared to participants in a control condition (Chancellor, et al., 2018). Similarly, in economic games, participants who have been helped by someone else give more money to an unrelated third party than those who have not been helped (DeSteno, et al., 2010). Generosity, it seems, can be contagious. If people underestimate the positive emotional impact their kindness will have on a recipient, then they should underestimate the positive behavioral consequences of their kindness as well.

Note also that examining a behavioral consequence of kindness tests another alternative interpretation of our results: that performers' mispredictions are driven by some version of selfreport bias among recipients. Recipients, for instance, may inflate their reported positive experience because they do not want to look ungrateful to the experimenters. Recipients in the control condition of Experiment 3, however, did not report being in especially positive moods, at least compared to recipients in the kindness condition. Nevertheless, documenting a similar result on behavior would suggest that participants' survey responses are honest reports of their own experience.

Experiment 4 tests this possibility by conceptually replicating the conditions from Experiment 3 in the laboratory while also giving recipients an opportunity to behave relatively 
more or less prosocially towards a third person. We predicted that performers would again underestimate the positive impact their prosocial act would have on a recipient, both on the recipient's emotional experience as well as on their kindness towards another person.

\section{Method}

Participants. We recruited participants $(\mathrm{N}=200)$ following the same gifting procedure as Experiment $2 b$, but from a community sample at a laboratory in the city center instead of from a university pool. Sampling participants from a more representative population provides evidence about the generality of our results.

We again targeted 50 pairs of participants in each of our two conditions (100 pairs total). Two participants in the act of kindness condition did not follow the experimenter's encouragement to give their gift away and instead kept it for themselves. Compared to conducting our experiment with a university population at an elite institution, sampling from the broader community introduces more variance on attention, experience, and understanding among our participants. One participant fell asleep during the course of the experiment and this person's pair was therefore excluded. Ten additional pairs involved at least one participant who failed an understanding check on how a dictator game (described below) works, such that the values they reported for the two parties in the exchange did not add up to the total pool of money available for allocation (that is, they were instructed in the experiment to provide two values that summed to $\$ 100$, but they were unable to do this). We excluded these participants for failing to understand the critical instructions of the game. This left a final sample of 174 participants: 46 estimators $\left(13\right.$ female; $\left.M_{\text {age }}=38.76, S D=14.72\right)$ and recipients $\left(17\right.$ female; $M_{\text {age }}=38.78, S D=$ $14.28)$ in the control condition and 41 performers (13 female; $\left.M_{\mathrm{age}}=36.15, S D=14.33\right)$ and recipients $\left(17\right.$ female; $\left.M_{\text {age }}=37.51, S D=13.93\right)$ in the kindness condition. 
Procedure. We conducted this experiment following the "lab store" procedure in Experiment $2 \mathrm{~b}$, using the conditions employed in Experiment 3 (in which participants were randomly assigned to either a kindness condition or to a control condition). More specifically, recipients in the kindness condition received a gift from another participant (from the "lab store"), whereas recipients in the control condition received a gift as an unexpected part of their compensation for the experiment and chose the gift themselves. Estimators in the control condition were told which item the recipient had chosen for himself or herself before they estimated that recipient's experience. All expected and actual evaluations were identical to those used in Experiment 2b, except that we did not include the awkwardness item due to inconsistent responses on that item across experiments. As in Experiment 2b, we included an exploratory measure of the item's perceived monetary value. Our primary dependent measures again were how "big" the act appeared to be and the recipient's mood.

After recipients received their item and completed the primary measures, both performers and recipients also read a description of a dictator game (Camerer, 2003; Forsythe, Horowitz, Savin, \& Sefton, 1994; Henrich, et al., 2004) that we explained was a separate experiment being run to fill out the remainder of the time in their experimental session. All participants who received an item (either from the experimenter or as an act of kindness from their partner) were assigned to the role of "decider" in this game. Specifically, they were told:

"You have been selected to serve in the role of 'decider' and in that role you will be asked to make a decision that could potentially earn you and/or another person (who you'll never meet) some money in addition to the payment you'll receive for your participation today. This other person has been assigned to the role of 'recipient.' As the decider, your task is simply to divide up $\$ 100$ between yourself and the recipient in 
whatever way you want. You'd get whatever amount you assign to yourself and the recipient would receive whatever was left over."

The instructions indicated that they would never meet the other person in this exchange in part to make clear that this was not their partner from the earlier portion of the experiment, whom they had met briefly in a waiting room prior to the beginning of the experimental session. They were further instructed that we would randomly select one decider's decision to actually be paid out in the exact way someone decided to allocate it, so that it was clear that the task involved real money and that their decision was consequential (we did in fact do this upon completion of data collection). These participants then indicated how they wanted to split the money, with a note that the two values they picked needed to sum to $\$ 100$.

Estimators and performers in what was ostensibly the previous experiment- those who did not receive an item from the "lab store"-were told what their partner was doing. That is, they were given the same details about the game, but were instructed that they would not actually be personally involved in it themselves. They were instead asked to predict their previous partner's behavior in this subsequent game. We expected that those who had just been on the receiving end of an act of kindness would give more to an anonymous person in the dictator game than recipients in the control condition, but that those who performed an act of kindness would underestimate the positive impact they had.

\section{Results}

Those who performed an act of kindness felt significantly better than normal $(M=2.07$, $S D=2.17)$, one-sample $t(40)=6.11, p<.0001, d=0.95$, and felt marginally better than estimators in the control condition $(M=1.15, S D=2.56), t(85)=1.80, p=.076, d=0.39$. 
As in Experiment 3, estimators and recipients in the control condition provided similar evaluations of how "big" the act seemed to be $(M \mathrm{~s}=5.22$ and 5.57, respectively, $S D \mathrm{~s}=2.56$ and 2.97), paired $t(45)=0.64, p=.528, d=0.09$. Estimators did, however, significantly underestimate how positive recipients would feel $(M \mathrm{~s}=2.07$ and 2.87 , respectively, $S D \mathrm{~s}=2.15$ and 1.73), paired $t(45)=2.08, p=.043, d=0.31$. Estimators and recipients did not differ in the estimated dollar value of the item received $(M \mathrm{~s}=\$ 3.71$ and $\$ 3.93$, respectively, $S D \mathrm{~s}=1.96$ and 1.46), paired $t(45)=0.66, p=.522, d=0.08$.

Replicating the results from the acts of kindness examined in Experiments 1a-3, performers in the kindness condition rated the act as significantly less "big" $(M=5.29, S D=$ 3.08) than recipients $\operatorname{did}(M=8.39, S D=1.59)$, paired $t(40)=6.65, p<.0001, d=1.14$. Performers $(M=2.68, S D=1.97)$ also significantly underestimated their recipient's mood $(M=$ 3.63, $S D=1.67)$, paired $t(40)=2.22, p=.032, d=0.35$. As in Experiment $2 \mathrm{~b}$, we observed nonsignificant differences between estimates of the item's dollar value between performers $(M=$ $\$ 3.84, S D=1.96)$ and recipients $(M=\$ 3.95, S D=1.39)$, paired $t(40)=0.36, p=.722, d=0.10$.

This pattern of results yielded a statistically significant interaction effect on the measure of how big the act was, $F(1,85)=14.30, p<.001$, and a nonsignificant interaction regarding the recipient's mood, $F<1, p=.799$. The magnitude of miscalibration on this latter dependent variable was, however, directionally larger in the kindness condition than in the control condition. Moreover, recipients in the kindness condition felt significantly more positive after receiving their item than recipients in the control condition, $t(85)=2.09, p=.040, d=0.45$.

Beyond its positive impact on the recipient's experience, the act of kindness had its predicted behavioral consequence on recipients. Specifically, recipients in the kindness condition were more generous in the amount they gave to a stranger in the subsequent dictator 
game $(M=\$ 48.02, S D=11.69)$ than were recipients in the control condition $(M=\$ 41.20, S D=$ 16.77), unequal variances $t(80.53)=2.22, p=.029, d=0.48$. Performers in the kindness condition, as predicted, underestimated how generous their recipients would be $(M=\$ 40.85, S D$ $=15.69)$, paired $t(40)=2.15, p=.038, d=0.34$, while estimators in the control condition did not significantly underestimate how generous their recipient would be $(M=\$ 37.15, S D=21.66)$, paired $t(45)=1.08, p=.285, d=0.16$ (see Figure 4$)$. Although the predicted interaction was nonsignificant, $F<1, p=.538$, expectations in the control and kindness conditions also did not differ significantly from each other, $t(85)=0.90, p=.369, d=0.19$. The pattern shown in Figure 4 suggests that performers may not fully appreciate the impact that their kindness will have on recipients' future kindness towards others.

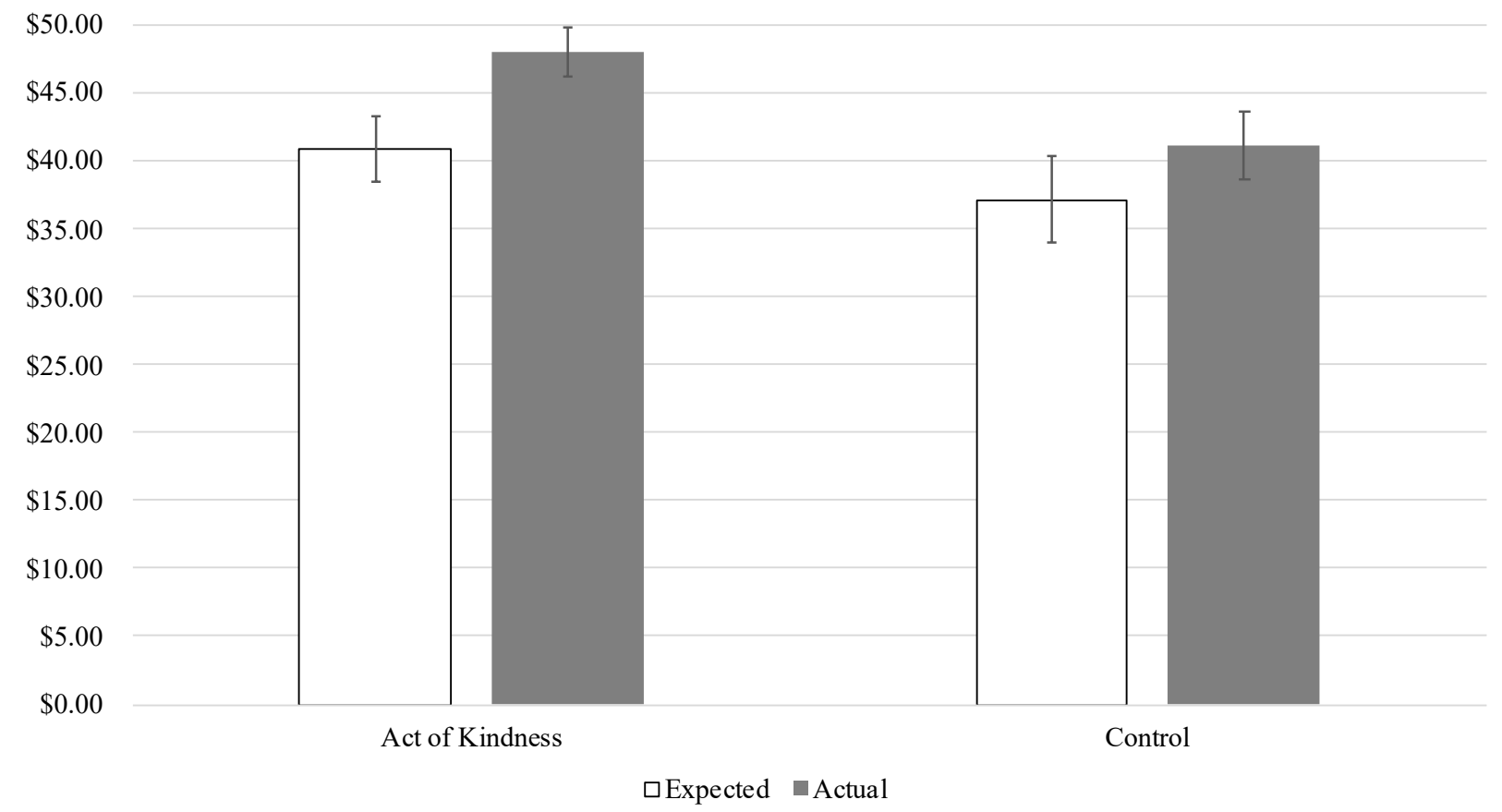

Figure 4. Expectations and actual behavior (for amount given) in a subsequent dictator game, either following an act of kindness or not, in Experiment 4. Error bars reflect standard errors. 


\section{Experiment 5a: Barrier to Kindness?}

We suggest that miscalibrated expectations about the positive impact of kindness matter because they can create a misplaced psychological barrier to being kinder in everyday life. Our experiments thus far, however, have not directly tested whether expectations about the impact of a kind act on a recipient guide people's choices to perform random acts of kindness. We did this in Experiment 5a by examining the extent to which people's expectations of a recipient's response were correlated with their likelihood of performing an act of kindness. Participants considered five different people for whom they could perform a random act of kindness. For each person, participants indicated how big the act would seem if they performed it and how they thought the recipient would feel as a result of them performing this act of kindness. After reporting their expectations, participants indicated how likely they would be to actually perform the given act for said person in real life.

\section{Method}

Participants. We recruited participants $\left(\mathrm{N}=101 ; 42\right.$ female; $\left.M_{\text {age }}=20.77, S D=1.59\right)$ to a campus laboratory at a large public university in the southern United States who completed this experiment in exchange for course credit. We targeted a sample size of 100 participants, with the final sample including one additional participant who arrived at the study location for the same session as the one hundredth participant.

Procedure. We recruited participants for a study about social relationships. We asked participants to think about the notion of performing acts of kindness for other people, with descriptions and examples closely following those provided to participants in the earlier experiments. We then asked participants to think of five specific people for whom they could potentially perform a random act of kindness. To help participants think broadly, they were 
asked to think of people from a variety of contexts in their life: "relatives, friends, teachers, coaches, teammates, employers, people you see often but don't interact with much for whatever reason, complete strangers." To elaborate on the possible range of others, we added, "Within the domain of family, you might think of a parent or sibling. You could think about the domain of friends, current or former teachers and coaches, colleagues and co-workers, community members like neighbors or other people you don't know quite as well in your community. You may even think about strangers who just happen to be accessible;" we explicitly mentioned that random acts of kindness can be done for different people, and that these people may respond differently to them.

For each target, participants indicated the person's initials, reported how they knew him or her, and briefly described what they could do for that person. Participants were then asked to think about what it would be like to actually perform such an act for each person and how each person would respond to their act of kindness. For each target, participants rated how big the act of kindness would seem on a scale from 0 ("Very Small") to 10 ("Very Large"), with the midpoint labeled "Moderate." They then rated how each recipient would feel on an 11-point scale ranging from -5 (Much More NEGATIVE Than Normal) to 5 (Much More POSITIVE Than Normal), with 0 (No different than normal) as the midpoint. Finally, participants indicated how likely they would be to really perform the given act of kindness for each person on a scale anchored at -5, "Very Unlikely," and 5, "Very Likely."

\section{Results}

Because we asked participants to indicate the likelihood of performing an act of kindness across multiple targets, we pre-registered an analysis plan to compute the average correlation across targets for both the measure of how big the act would seem and participants' prediction of 
recipient mood and the likelihood to actually perform a random act of kindness. This analysis allows us to assess how variance in the expected impact is related to variance in the likelihood of engaging in prosocial action (see also Kumar \& Epley, 2018). As pre-registered, we excluded six participants from analyses who reported no difference in the likelihood of performing an act across targets, making it statistically impossible to calculate a correlation, and up to three on an item-by-item basis who reported no differences on the other two measures (one for how big the act would seem and three for expectations of the recipient's mood following the random act of kindness being performed for them).

Contrary to our predictions, participants' likelihood of performing random acts of kindness was nonsignificantly correlated, on average, with their perceptions of how big the act would seem (mean correlation $=.08), t(93)=1.43, p=.157, d=0.15$. As predicted, however, participants' likelihood of performing a random act of kindness was significantly positively correlated with their expectations of how their action would make the recipient feel (mean correlation $=.21), t(91)=3.92, p<.001, d=0.41$. That is, the more participants thought their prosocial act would increase a recipient's positive mood, the more likely they reported being to actually perform the random act of kindness. Additional post-hoc analyses using repeated measures correlation (Bakdash \& Marusich, 2017) also yielded a significant correlation between expected positive mood and likelihood of performing the acts, $r=.21, p<.001$, as did a multilevel model, $b=.23, S E=.04, t(502.8)=5.50, p<.001$ (see also Zhao \& Epley, 2021a). These results suggest that the likelihood of performing a random act of kindness may be based at least partly on the recipient's expected reaction to the act. Underestimating how positive a recipient will feel—as we consistently observed participants doing in our earlier experimentscould therefore lead to fewer prosocial acts than might be optimal in daily life. 


\section{Experiment 5b: Lifting the Barrier}

Experiment 5a suggests that people's expectations could create a miscalibrated psychological barrier to behaving more prosocially in everyday life. The strongest causal test of this hypotheses would experimentally manipulate people's expectations to measure their impact on interest in performing a random act of kindness. We conducted this test in Experiment $5 \mathrm{~b}$ by manipulating whether potential performers of a random act of kindness were focused on the warmth conveyed by their action or the competence conveyed by it. As we theorized earlier, we predict that people underestimate the positive impact of their random acts of kindness because they focus inordinately on the competency conveyed by their action (e.g., the objective quality of the gift) while recipients derive value also from the warmth conveyed by act. This suggests that those performing an act of kindness could recognize that recipients will derive some positive experience from the warmth conveyed by the action, but that they otherwise overlook this aspect of their action. This predicts that aligning the perspective of those performing a random act of kindness with recipients' perspectives, by explicitly focusing attention on the warmth conveyed by the action, should increase people's interest in performing a random act of kindness. We tested this prediction directly in Experiment $5 \mathrm{~b}$ by measuring people's interest in performing an act of kindness after focusing them explicitly on the warmth conveyed by their action or its competence. We also included a dichotomous behavioral measure in this experiment, as participants were given the choice to keep a gift card for themselves or give it away to someone else as an act of kindness. We predicted that participants would be more interested in performing an act of kindness in the warmth-focused condition than in the competence-focused condition.

\section{Method}


Participants. We targeted recruitment of 100 participants in order to obtain 50 in each of two experimental conditions. Due to the COVID-19 pandemic, these 100 participants (62 female; $\left.M_{\text {age }}=28.44, S D=11.00\right)$ completed the experiment through an online "Virtual Lab" coordinated by a University research center in exchange for $\$ 1$.

Procedure. We conducted this experiment remotely via a study link sent to participants. We first told participants that, "We understand that these are hard times for everyone, and so we want to do something positive for our participants," and that "One of the reasons these times are so trying right now is because, due to the pandemic, we have less contact with other people that we might have previously interacted with more often." We then asked participants to think of a friend or acquaintance who they used to see quite regularly but had not interacted with in the past year (while social distancing policies were the recommended guideline), whose contact information they also knew.

After writing down this person's initials, we told participants that we were giving away $\$ 5$ gift cards to a coffee shop to all study participants and asked them to think about possibly keeping the gift card for themselves or giving it away to the person whose initials they had provided as a random act of kindness.

Participants randomly assigned to the competence-focused condition then read that "choosing just the right gift for these occasions can really make another person happy." They were told that they would later be able to give the gift card away or keep it for themselves instead, but that they should take a moment to consider what it would be like if they actually gave the gift card to the person they had mentioned earlier. They were then asked to rate how confident they were that this was the right thing to give for this occasion $(0=$ Not at all 
confident; 10 = Extremely confident), as well as how effective this gift card would be in making the other person happier $(0=$ Not at all effective; $10=$ Extremely effective $)$.

Participants randomly assigned to the warmth-focused condition, in contrast, first read that "it's really the kindness behind these acts that counts for making another person happy." They were similarly told that they would later be able to give the gift card away or keep it for themselves instead. After being asked to think about what it would be like if they gave the gift card away, they were asked to rate how much kindness would be conveyed by their act $(0=$ None at all; $10=\mathrm{A}$ great deal $)$ and how nice the other person would believe the act was $(0=$ Not at all nice; $10=$ Extremely nice).

In order to test whether participants report being more interested in engaging in kindness when focused on warmth or competence, our key dependent variable examined participants' preferences for keeping the gift card for themselves versus giving it away as a random act of kindness. Participants in both conditions responded on a scale with anchors at -5 , "Very interested in KEEPING it for myself," and 5, "Very interested in GIVING it away" (with the midpoint, 0, labeled "Equally interested"). Finally, participants were asked to make a binary choice about whether to keep the gift card for themselves or give the gift card away as a random act of kindness. Participants were told "Whatever you'd like to do is fine." Links to obtain the gift cards were then actually sent to either the participant themselves or the person they chose at the beginning of the experiment, depending on their decision.

\section{Results}

As predicted, participants reported being significantly more interested in giving their gift card away as an act of kindness in the warmth-focused condition $(M=1.74, S D=3.24)$ than in the competence-focused condition $(M=0.38, S D=3.37), t(98)=2.06, p=.042, d=0.41$. We 
pre-registered our hypothesis that responses on the binary choice measure would be in the same direction as the primary dependent measure (the continuous measure of interest), but that our sample may not have been large enough for this effect to be statistically significant. This is indeed what we observed: A greater proportion of participants gave the gift card to their old friend or acquaintance in the warmth condition (30 out of $50 ; 60 \%$ ) than in the competence condition $(25$ out of $50 ; 50 \%)$, but this result was statistically nonsignificant, $\chi^{2}(1, N=100)=$ $1.01, p=.315$

The ratings of confidence/effectiveness and kindness/niceness were designed to serve as the manipulation focusing participants on either the warmth behind their act or the competency conveyed by it, but we also anticipated that participants would report more positive expectations in the warmth condition than in the competence condition. All ratings were provided on 11-point Likert scales, but caution is warranted when making a direct comparison between these ratings because the anchor labels on them were different. Nevertheless, we averaged the confidence and effectiveness items $(r=.81, p<.001)$ into a competence composite and averaged the two warmth items $(r=.75, p<.001)$ into a warmth composite. As predicted, participants reported more positive expectations of warmth $(M=7.94, S D=1.88)$ than competence $(M=6.73, S D=$ 2.66), $t(98)=2.63, p=.010, d=0.53$. Directing participants' attention to focus on the warmth conveyed by their act of kindness led to more positive expectations, which all prior experiments suggest would be likely to be more aligned with how recipients are also evaluating the action, and also increased participants' interest in performing a random act of kindness. Altering people's expectations about how a recipient will construe a prosocial act could affect their willingness to behave prosocially, suggesting that people's tendency to underestimate how 
positively a recipient would respond to an act of kindness creates a misplaced barrier to behaving more prosocially in everyday life.

\section{General Discussion}

Prosocial actions, such as performing random acts of kindness, tend to improve wellbeing for both those who perform prosocial acts as well as for those who receive them. Indeed, those who performed a random act of kindness in our experiments reported feeling significantly more positive than they normally do, and two of the experiments confirmed that performers felt better than participants who were not given the opportunity to perform a random act of kindness. Another found that performers of acts of kindness felt more positive after being kind than they reported feeling at the beginning of the experiment. Being more prosocial did not come at a cost to people's own wellbeing; it enhanced it.

Daily life, however, affords many opportunities for engaging in these sorts of prosocial activities that people may not take. We believe our research suggests one possible reason why: that those performing random acts of kindness undervalue the positive impact they are having on recipients. People's choices are often guided by either an implicit or explicit calculation of expected value (Becker, 1993). Underestimating how positive a recipient would feel after even a small act of kindness could lead people to engage in prosocial actions less often than might be optimal for both their own and others' wellbeing.

Across a variety of different actions, in many different contexts, performers systematically perceived their random act of kindness to be a more minor action than recipients perceived it to be, and also systematically underestimated how positive recipients would feel afterwards. Performers were not confused, of course, that recipients would feel good about their experience. In all cases performers expected recipients to feel more positive than they normally 
do. Nevertheless, performers were still systematically miscalibrated as recipients felt even better than expected.

Experiment 3 suggests one potential reason for this miscalibration. Established research has documented an asymmetry such that observers evaluate an action primarily on the dimension of warmth, whereas actors tend to be focused on competence (Abele \& Wojciszke, 2007; Fiske, Cuddy, \& Glick, 2007; Wojciszke, 1994). This perspective gap could lead performers to focus on details of the act itself — what was actually done for another person — rather than on the interpersonal meaning of the action — specifically, the warmth conveyed directly to the recipient of an act of kindness. To the extent that recipients are affected both by the action itself as well as by the warmth conveyed through it, they may derive more positive value from the act than performers anticipate. Experiment 3 provides some support for this mechanism. Here, participants expected that recipients would feel equally positive after getting a gift regardless of whether it was done as an act of kindness from another person or not, suggesting that people were not taking the warmth conveyed by an act of kindness into account when anticipating a recipient's reaction. Recipients, themselves, however, felt better receiving a gift that was part of an act of kindness.

Experiment 4 also provides some support for this mechanism, although not as consistently. In this experiment, estimators and recipients differed in their evaluation of how "big" a prosocial act seemed in the kindness condition but not in the control condition.

Likewise, estimators did not differ in their predictions of indirect reciprocity between the kindness and control conditions, even though recipients were significantly more generous in the kindness condition. However, estimators significantly underestimated the recipients' positive mood in both the kindness and control conditions, albeit the former effect was directionally 
larger than the latter. Collectively, these two experiments suggest that people are more capable of understanding what it feels like to receive a gift than understanding what it feels like to receive an act of kindness. Getting a cupcake is known to be good, but getting a cupcake as an act of kindness seems to be surprisingly good.

Given some inconsistency in our results, more research is obviously needed to understand the importance of this perspective asymmetry in producing the miscalibrated expectations we observed consistently in our experiments. We have begun this testing by conducting an additional survey asking people to imagine either being performers or recipients of an act of kindness. Notice that the perspective-based asymmetry we have articulated suggests that being a recipient of an act of kindness may be particularly hard to appreciate, because the warmth of a prosocial action comes from the positive intent personally directed at the recipient of the prosocial act. This targeted nature of prosociality may make it difficult to appreciate the recipient's perspective in a prosocial exchange. As an initial test of this possibility, we asked a group of participants $(N=98)$ to imagine being either performers or recipients of an act of kindness. Specifically, we asked them to imagine the situation involving giving or receiving a cupcake at a large public park in the downtown area of a major American city. Here, when the recipients were not actually receiving a prosocial act but were simply imagining it, we observed a nonsignificant difference in predictions of positive mood between perspectives $\left(M_{\text {PerformerPrediction }}=2.96, S D_{\text {PerformerPrediction }}=1.83 ; M_{\text {RecipientPrediction }}=3.02, S D_{\text {RecipientPrediction }}=\right.$ $1.65)$, paired $t(48)=0.18, p=.85$, with average predictions being closer to what we observed among performers of this act of kindness in Experiment 3 than among recipients. Of course, we cannot statistically compare these results to those of Experiment 3 given that we did not randomly assign these observers to a separate condition in that experiment. However, our 
mechanism predicts that third person observers of a prosocial exchange should also underestimate how positive a recipient will feel, meaning that the tendency to undervalue the positive consequences of prosocial exchanges could be a widespread phenomenon.

Despite the consistent pattern we observed when predicting a recipient's mood, we found inconsistent evidence when asking people to predict how awkward a recipient will feel. This is a potentially negative consequence of prosocial interaction. Previous research (Boothby \& Bohns, 2021; Kumar \& Epley, 2018; Zhao \& Epley, 2021a) has found that for certain prosocial actslike expressing gratitude and compliments_-people tend to both underestimate benefits and overestimate costs. In particular, expressors of gratitude are more worried about their recipients feeling awkward than they ought to be. We found initial evidence for a similar pattern of results for acts of kindness more generally in Experiment 1a but did not observe significant effects on awkwardness in Experiments $1 \mathrm{~b}$ and $2 \mathrm{~b}$. Miscalibration about awkwardness may be unique to instances like writing a gratitude letter because of the personal nature of that sort of prosocial action, compared to the impersonal nature of a random act of kindness when there may be little or no interaction between those performing the act and recipients. In many of our paradigms, in fact, participants were not even engaging in a direct exchange: the item was transferred from performer to recipient through a research assistant. Future research should examine the particular conditions that cause anticipated awkwardness to create a psychological barrier to prosocial actions.

We believe the results of our experiments are part of a broader tendency to underestimate the positive consequences of a wide variety of prosocial actions, not just including gratitude and random acts of kindness, because the mechanism underlying these results should apply to almost any action that comes with a clear prosocial intent. That said, there are different kinds of 
prosocial acts, and our results may vary meaningfully across them. Some prosocial acts are typically done for closer friends that have been nice to you, whereas others involve randomly doing nice things for other people, strangers who are not at all related or connected to you. Experiment 1a involved a mix of these types of people, Experiment $1 \mathrm{~b}$ focused exclusively on known others, and Experiments 2a-4 moved to interactions between strangers. Earlier research on prosociality has found that doing good for strong social ties leads to more happiness for performers than using resources to benefit weak social ties (Aknin, Sandstrom, Dunn, \& Norton, 2011). But other prior studies have maintained that interactions with weak ties can be surprisingly powerful for wellbeing (Dunn, Biesanz, Human, \& Finn, 2007; Epley \& Schroeder, 2014; Sandstrom \& Dunn, 2014; Schroeder, et al., in press).

We think it would be very interesting to systematically investigate how our findings would be similar or different depending on the nature of one's relationship with a recipient. People may, for instance, be particularly likely to underestimate the benefits of performing random acts of kindness for others who they do not know well because they are especially likely to overlook the positive impact of warmth when no existing interpersonal relationship has been established or is foreseen in the future. Indeed, existing research indicates that expectations about intimate conversations are systematically more miscalibrated for strangers than for friends (Kardas, Kumar, \& Epley, 2022). Similarly, people who express support to more distant acquaintances in need tend to expect less positive responses than those who express support to others who are in closer relationships with them. Actual responses to this social support, however, were similarly positive (Dungan, et al., in press). There can be more uncertainty in one's mind about how someone will react to one's warmth when said someone is less well known, but actual experiences with even previously unknown others may not vary as much as 
people expect. Potential differences across different types of relationships may be larger for expectations than for experiences.

Our proposed mechanism about an asymmetry in attention paid to competence versus warmth suggests that there could be some meaningful cross-situational variability in the results we observed. In particular, people, contexts, and cultures that are particularly likely to draw people's attention to the warmth conveyed by their prosocial act, compared to details regarding competence of the act itself, should reduce the asymmetry we have observed here. Those high in conscientiousness, for instance, may be more attentive to expressions of interpersonal warmth than those low in conscientiousness, and may therefore appreciate the value of a prosocial action to a recipient as a result. Likewise, cultures that emphasize the importance of intergroup harmony and cohesion might also be better able to appreciate the positive consequences of their prosocial actions towards ingroup members. One important existing result is that prosociality seems to be a positive experience for those performing it around the globe (Aknin, et al., 2013). The extent to which people's expectations about prosociality vary across people and cultures is, as yet, an open question.

Our proposed mechanism also suggests some important boundary conditions on our results. Specifically, we investigated acts that were both intended to be prosocial and were likely perceived to be prosocial, wherein the positive experience of being on the receiving end of these actions comes from the warmth it conveys. Our theorizing would predict very different results for actions that are intended to be more prosocial than they are perceived to be, such as gift exchanges that can sometimes seem like obligated or ingratiating acts (Flynn \& Brockner, 2003), or when the prosocial intent is clearer to the giver than it is to the receiver (Zhang \& Epley, 2012), simply because recipients would value these acts less because they conveyed less warmth. 
In contrast, we would expect that prosocial actors would underestimate a recipient's positive response even more in cases where the prosocial intent was actually weaker among performers than the recipients perceived it to be, such as receiving a desired gift that the performers put no thought or effort into (Zhang \& Epley, 2012).

Interestingly, the participants in our first experiment indicated that they wished they performed random acts of kindness for others more often. If people want to engage in prosocial acts more frequently, why don't they? This research suggests that one reason may be because they misunderstand the consequences of being kind to other people. Those who do something positive for someone else may feel like their small actions are relatively inconsequential, not having much impact at all. But buying coffee for another person, sending a card just because, or inquiring about one's day with a simple "Hi, How Are You?" could be bigger and more meaningful than people apparently expect. These mistaken beliefs potentially keep people from being prosocial enough, resulting in them missing out on opportunities to maximize their own and others' wellbeing. Our experiments indicate that both performers and recipients might be somewhat better off if they engaged in random acts of kindness more often. Even better off, in fact, than they might expect. 


\section{References}

Abele, A. E., \& Wojciszke, B. (2007). Agency and communion from the perspective of self versus others. Journal of Personality and Social Psychology, 93, 751-763.

Aknin, L. B., Barrington-Leigh, C. P., Dunn, E. W., Helliwell, J. F., Burns, J., Biswas-Diener, R., Kemeza, I., Nyende, P., Ashton-James, C., \& Norton, M. I. (2013). Prosocial spending and well-being: Cross-cultural evidence for a psychological universal. Journal of Personality and Social Psychology, 104(4), 635-652.

Aknin, L. B., Sandstrom, G. M., Dunn, E. W., \& Norton, M. I. (2011). It's the recipient that counts: Spending money on strong social ties leads to greater happiness than spending on weak social ties. PloS One, 6 .

Bakdash, J. Z., \& Marusich, L. R. (2017). Repeated measures correlation. Frontiers in Psychology, 8, 1-13.

Becker, G. S. (1993). Nobel lecture: The economic way of looking at behavior. Journal of Political Economy, 101, 385-409.

Boothby, E. J., \& Bohns, V. K. (2021). Why a simply act of kindness is not as simple as it seems: Underestimating the Positive Impact of Our Compliments on Others. Personality and Social Psychology Bulletin, 47, 826-840.

Boothby, E. J., Cooney, G., Sandstrom, G. M., \& Clark, M. S. (2018). The liking gap in conversations: Do people like us more than we think? Psychological Science, 29, 17421756.

Camerer, C. (2003). Behavioral game theory: Experiments in strategic interaction. Princeton: Princeton University Press. 
Chancellor, J., Margolis, S., Jacobs Bao, K., \& Lyubomirsky, S. (2018). Everyday prosociality in the workplace: The reinforcing benefits of giving, getting, and glimpsing. Emotion, $18(4), 507-517$.

Curry, O. S., Rowland, L. A., Van Lissa, C. J., Zlotowitz, S., McAlaney, J., \& Whitehouse, H. (2018). Happy to help? A systematic review and meta-analysis of the effects of performing random acts of kindness on the well-being of the actor. Journal of Experimental Social Psychology, 76, 320-329.

DeSteno, D., Bartlett, M. Y., Baumann, J., Williams, L. A., \& Dickens, L. (2010). Gratitude as moral sentiment: Emotion-guided cooperation in economic exchange. Emotion, 10, 289293.

Diener, E., \& Seligman, M. E. P. (2002). Very happy people. Psychological Science, 13(3), 8184.

Dungan, J. A., Mungia Gomez, D., \& Epley, N. (in press). Too reluctant to reach out: Receiving support is more positive than expressers expect. Psychological Science.

Dunn, E. W., Aknin, L. B., \& Norton, M. I. (2008). Spending money on others promotes happiness. Science, 319, 1687-1688.

Dunn, E. W., Biesanz, J. C., Human, L. J., \& Finn, S. (2007). Misunderstanding the affective consequences of everyday social interactions: The hidden benefits of putting one's best face forward. Journal of Personality and Social Psychology, 92, 990-1005.

Epley, N., Keysar, B., Van Boven, L., \& Gilovich, T. (2004). Perspective taking as egocentric anchoring and adjustment. Journal of Personality and Social Psychology, 87, 327-339.

Epley, N., Kardas, M., Zhao, X., Atir, S., \& Schroeder, J. (in press). Undersociality:

Miscalibrated social cognition can inhibit social connection. Trends in Cognitive 


\section{Sciences.}

Epley, N., Kumar, A., Dungan, J., \& Echelbarger, M. (2022). A prosociality paradox: Miscalibrated social cognition can inhibit prosocial action. Manuscript submitted for publication.

Epley, N., \& Schroeder, J. (2014). Mistakenly seeking solitude. Journal of Experimental Psychology: General, 143(5), 1980-1999.

Fiske, S. T., Cuddy, A. J. C., \& Glick, P. (2007). Universal dimensions of social cognition: Warmth and competence. Trends in Cognitive Sciences, 11, 77-83.

Flynn, F. J., \& Brockner, J. (2003). It's different to give than to receive: Predictors of givers' and receivers' reactions to favor exchange. Journal of Applied Psychology, 88, 1034-1045.

Flynn, F. J., \& Lake, V. K. B. (2008). If you need help, just ask: Underestimating compliance with direct requests for help. Journal of Personality and Social Psychology, 95, 128-143.

Forsythe, R., Horowitz, J. L, Savin, N. E., \& Sefton, M. (1994). Fairness in simple bargaining experiments. Games and Economic Behavior, 6(3), 347-369.

Grant, A. M., \& Sonnentag, S. (2010). Doing good buffers against feeling bad: Prosocial impact compensates for negative task and self-evaluations. Organizational Behavior and Human Decision Processes, 111, 13-22.

Gray, K., Ward, A.F., \& Norton, M.I. (2014). Paying it forward: Generalized reciprocity and the limits of generosity. Journal of Experimental Psychology: General, 143, 247-254.

Helliwell, J. F., \& Putnam, R. D. (2004). The social context of well-being. Philosophical Transactions of the Royal Society of London B, 359, 1435-1446.

Henrich, J., Boyd, R., Bowles, S., Camerer, C., Fehr, E., \& Gintis, H. (2004). Foundations of Human Sociality: Economic Experiments and Ethnographic Evidence from Fifteen 
Small-Scale Societies. Oxford University Press.

Holt-Lunstad, J., Smith, T. B., \& Layton, J. B. (2010). Social relationships and mortality risk: A meta-analytic review. PLoS Medicine, 7(7).

House, J. S., Landis, K. R., \& Umberson, D. (1988). Social relationships and health. Science, $241,540-545$.

Kahneman, D., \& Deaton, A. (2010). High income improves evaluation of life but not emotional well-being. Proceedings of the National Academy of Sciences, 107, 16489-16493.

Kardas. M., Kumar, A., \& Epley, N. (2022). Overly shallow? Miscalibrated expectations create a barrier to deeper conversation. Journal of Personality and Social Psychology, 122(3), 367-398.

Kumar. A., \& Epley, N. (2018). Undervaluing gratitude: Expressers misunderstand the consequences of showing appreciation. Psychological Science, 29, 1423-1435.

Layous, K., Nelson, S. K., Oberle, E., Schonert-Reichl, K., \& Lyubomirsky, S. (2012). Kindness counts: Prompting prosocial behavior in preadolescents boots peer acceptance and well being. PloS One, 7.

Luo, Y., Hawkley, L. C., Waite, L. J., \& Cacioppo, J. T. (2012). Loneliness, health, and mortality in old age: A national longitudinal study. Social Science \& Medicine, 74(6), 907-914.

Lyubomirsky. S., Sheldon, K. M., \& Schkade, D. (2005). Pursuing happiness: The architecture of sustainable change. Review of General Psychology, 9, 111-131.

Myers, D. G. (2000). The funds, friends, and faith of happy people. American Psychologist, $55(1), 56-67$.

Newark, D. A., Bohns, V. K., \& Flynn, F. J. (2017). A helping hand is hard at work: Help- 
seekers' underestimation of helpers' effort. Organizational Behavior and Human Decision Processes, 139, 18-29.

Sandstrom, G. M., \& Dunn, E. W. (2014). Social interactions and well-being: The surprising power of weak ties. Personality and Social Psychology Bulletin, 40, 910-922.

Schroeder, J., Lyons, D., \& Epley, N. (in press). Hello, stranger? Pleasant conversations are preceded by concerns about starting one. Journal of Experimental Psychology: General.

Van Boven, L., Loewenstein, G., Dunning, D., \& Nordgren, L. F. (2013). Changing places: A dual judgment model of empathy gaps in emotional perspective taking. In J. M. Olson \& M. P. Zanna (Eds.), Advances in Experimental Social Psychology (Vol. 48, pp. 118-171). San Diego, CA: Academic Press.

Wojciszke, B. (1994). Multiple meanings of behavior: Construing actions in terms of competence or morality. Journal of Personality and Social Psychology, 67, 222-232.

Zhang, Y., \& Epley, N. (2012). Exaggerated, mispredicted, and misplaced: When "it's the the thought that counts" in gift exchanges. Journal of Experimental Psychology: General, $141,667-681$.

Zhao, X., \& Epley, N. (2021a). Insufficiently complimentary? Underestimating the positive impact of compliments creates a barrier to expressing them. Journal of Personality and Social Psychology, 121, 239-256.

Zhao, X., \& Epley, N. (2021b). Kind words do not become tired words: Undervaluing the positive impact of frequent compliments. Self and Identity, 20, 25-46.

Zhao, X., \& Epley, N. (in press). Surprisingly happy to have helped: Underestimating prosociality creates a misplaced barrier to asking for help. Psychological Science. 